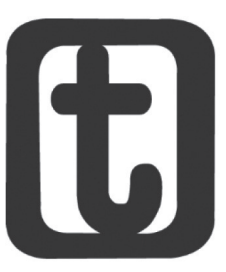

\title{
A QUESTÃO DOS DOCUMENTOS PROFISSIONAIS NO SERVIÇO SOCIAL
}

\author{
The question of professional documents in Social Work
}

\section{Ludson Rocha Martins ${ }^{1}$}

\section{RESUMO}

O presente texto realiza indicações práticas para formulação e utilização de laudos, relatórios e pareceres sociais, enfatizando sua conexão com o problema do estudo social, compreendido enquanto processo de análise da realidade em matéria de Serviço Social. As considerações realizadas focam-se na caracterização crítica dos instrumentais supracitados, por meio de uma abordagem sintética e didática.

\section{PALAVRAS-CHAVE}

Serviço Social. Estudo social. Instrumentos de trabalho do assistente social.

\section{ABSTRACT}

The paper makes practical indications for the formulation and use of social technical report and social technical opinion, emphasizing its connection with the problem of social study, understood as a process of analysis of reality in matters of Social Work. The considerations made are focused on the critical characterization of the aforementioned instruments, through a synthetic and didactic approach.

\section{KEYWORDS}

Social Work. Social study. Social worker job tools.

\footnotetext{
${ }^{1}$ Assistente Social pelas Prefeituras: de Nova Lima (PNL, Nova Lima (MG), Brasil). Praça Bernardino de Lima, $n^{\circ} 80$, Centro, Nova Lima (MG), CEP.: 34000-970; e Prefeitura de Pedro Leopoldo (PPL, Pedro Leopoldo (MG), Brasil) R. Cristiano Otoní, $n^{\circ}$ 555, Centro, Pedro Leopoldo (MG), CEP.: 33600-000. Mestre em Serviço Social pela Universidade Federal de Juiz de Fora (UFJF, Juiz de Fora (MG), Brasil). E-mail: <ludson@outlook.com>.
} 


\section{INTRODUÇÃO}

A sistematização da prática é um dos grandes desafios do Serviço Social, especialmente em suas correntes progressistas, que precisam aperfeiçoar suas análises sobre o tema. Em que pese o esforço de muitos profissionais, existem ainda grandes lacunas teóricas a serem superadas, por meio de investigações diversas, capazes de expor exemplos interventivos e problematizar estratégias de atuação.

Nesta área um elemento fundamental são os documentos profissionais: os registros produzidos a partir das competências e atribuições do assistente social, constituindo laudos, relatórios e pareceres. Tais instrumentos possuem um papel singular na cultura do Serviço Social, integrando há muito a formação profissional, seja como veículo de emissão da opinião do assistente social, seja como mecanismos institucionais de fixação de experiências, realização encaminhamentos e solicitações.

A força do problema é demonstrada por seu histórico de debates, cuja trajetória evoca os primórdios da categoria, remetendo à discussão daquilo que as vertentes conservadoras e reacionárias chamaram de "método profissional" (RICHMOND, 1950; 1995; VIEIRA, 1977; RODRIGUES DA SILVA, 2006).

Com efeito, o Serviço Social Tradicional, desde as pioneiras, erigiu a sistematização da prática como plano central da legitimidade e especificidade profissional (NETTO, 2007; MONTAÑO, 2011; MARTINS, 2014; 2016). Nesta perspectiva os instrumentos e as técnicas eram vistos não apenas como estratégias de ação, mas como a manifestação direta de um saber exclusivo dos assistentes sociais. Daí, inclusive, a profusão de análises e diagnoses; o volume de obras dedicadas a quantificação de "desvios", aspirações "patológicas"; ao registro e encaminhamento de carências; depravações morais, e etc.

A tônica da concepção conservadora, como amplamente conhecido, era a elaboração de procedimentos que fossem em si mesmos suficientes para expor as demandas dos "clientes" da profissão. As metodologias de "caso", "grupo" e "comunidade" 
são exemplos típicos de tal perspectiva. Nelas os documentos profissionais seriam dispositivos que expressariam a cientificidade do Serviço Social, seja pela caracterização precisa das situações problema derivadas do conflito entre o indivíduo e seu meio; pela adequação do comportamento do sujeito no grupo; ou pela promoção do desenvolvimento comunitário (em sintonia com o Estado e a empresa) (RICHMOND,1995; AMMANN, 1982; KONOPKA, 1972).

A técnica era, assim, um elemento decisivo do reconhecimento profissional, nas suas várias dimensões e aplicações. Seria pelo seu emprego, sobretudo na forma de documentos, que o assistente social se afirmaria, distinguindo-se do agente assistencial não profissionalizado.

Evidentemente, essa concepção peculiar tem por base um pensamento de corte organicista, que supõe a existência do sistema social sempre em estado de equilíbrio. Nela, haveria uma condição normal de funcionamento da sociedade, cuja característica seria a correspondência entre as aspirações e práticas dos sujeitos com os valores culturais e recursos sociais a eles disponibilizados. O descompasso entre as estruturas socioculturais, os objetivos e as condutas individuais apontaria para a existência de um estado patológico do sujeito, do grupo ou da comunidade, que deveria ser trabalhado num processo de reforma moral.

Caberia ao assistente social, nesses termos, registrar os problemas que atingem os agentes individuais, de forma isolada, ou em sua dinâmica grupal, interpretando e encaminhando sua correção.

Nesta esfera a concepção richmondiana aparece como eixo fundante do ideário tradicional. Um de seus pilares é a noção de diagnóstico,

[...] definido como [...] a tentativa para se formar um juízo tão exato quanto possível da situação, da personalidade dum ser humano que tenha qualquer necessidade social, situação e intencionalidade estas em relação aos outros seres humanos de quem ele dependa ou que dependam dele, em relação também as instituições sociais de sua comunidade (RICHMOND, 1950, p. 310). 
Este processo, tal como visto por Richmond (1950), é o estudo que procura desvelar as inclinações da personalidade, esclarecendo a conexão entre as disposições individuais, os conflitos e os problemas sociais. Nele, a atuação do assistente social se realizaria mediante um conhecimento de natureza essencialmente indutiva, tendo-se em vista que "[...] o saber por evidência é o saber por ter visto, por ter sentido de modo incontestável [...]" (RICHMOND apud RODRIGUES DA SILVA, 2006, p. 6). Assim, o conhecimento que fundamenta a prática seria a conjugação lógica de várias inferências, um "[...] processo de raciocínio que nos permite transitar de um fato conhecido para outro desconhecido. Daí que de "[...] muitos casos particulares podemos apreender uma verdade a generalizar” (RICHMOND, 1950, p. 72).

Ou seja, da categorização dos problemas sociais recorrentes e significativos surge a interpretação que informaria qualquer diagnóstico, cuja condução demandaria um trabalho que pudesse abranger

[...] todos os fatores principais que importam à reconstrução social, com inclusão de todos os dados sobre que se possa afirmar o tratamento social a empreender. Nesta seleção dos elementos deve a trabalhadora social evitar sempre qualquer preferência por fatores causais, resultante de impulsos, predisposições ou simpatias pessoais (RICHMOND, 1950, p. 305).

É possível perceber as implicações de uma tal visão para o debate sobre os documentos elaborados por assistentes sociais. $\mathrm{Na}$ discussão tradicionalista laudos, relatórios e pareceres eram veículos para opinião profissional, emitida após um estudo que visava auxiliar o processo de intervenção sob uma realidade compreendida a partir de uma ótica "clínica". Daí que tais registros tomassem a forma expressa do prontuário, não por acaso bastante valorizada por Mary Richmmond (1950).

Entre os anos 1970 e 1980 a herança clínica foi implodida na América Latina e no Brasil pelo Movimento de Reconceituação e pela Renovação Profissional², que colocaram em xeque o seu

${ }^{2}$ Conforme lamamoto (2009) a Reconceituação (que se estendeu de 1965 a 1975) 
caráter unilateral e unilateralizante; a sua fragilidade teórica (assentada em diretrizes interventivas de tom manualizado), bem como sua orientação conservadora, funcional aos interesses dos grupos e classes hegemônicas.

Questionou-se a importação não mediatizada de modelos de atuação europeus e norte-americanos; a intenção de neutralidade dos processos de trabalho; o componente de controle social que subscrevia a prática dos assistentes sociais; a recusa profissional à grande teoria, dentre outras dimensões do ideário tradicionalista (NETTO, 2011). Contudo, se a crítica progressista foi capaz de apontar as insuficiências e debilidades do pensamento conservador, ainda encontra dificuldades para elaborar alternativas para guiar a intervenção profissional. Isto é, a pesquisa e a literatura do Serviço Social foram atualizadas, numa grande ruptura com as concepções do passado, porém a prática profissional encontrou tardiamente referências para que se efetivasse em sintonia com os novos princípios que marcam o trabalho do assistente social (SANTOS, 2006; REIS, 1998; VASCONCELOS, 2002).

Isso afetou toda discussão técnico-operativa, reverberando sobre o debate acerca dos documentos profissionais. A falta de indicações mínimas para a elaboração de laudos, pareceres e relatórios (dentre outros tipos de registros) criou um vazio nas discussões do Serviço Social, dificultando o trabalho, a formação e a pesquisa profissional.

Apenas recentemente importantes esforços foram envidados para enfrentar tal situação, por meio do estudo das condicionantes do mercado de trabalho, bem como dos instrumentos e técnicas usados pelos assistentes sociais (TRINDADE, 2001; LEWGOY;

consistiu num amplo movimento, efeito e causa de múltiplas transformações no Serviço Social, a partir crítica aos padrões tradicionais que informavam a prática, a formação e a teoria da profissão. Suas bandeiras incluíam a aproximação dos assistentes sociais de seus usuários (os "oprimidos"), o fortalecimento teórico e técnico da categoria, bem como a valorização das particularidades da profissão na América Latina. Já a "Renovação do Serviço Social Brasileiro foi uma dinâmica diferente que surgiu a partir da obstrução da Reconceituação pelo conservadorismo que emergiu junto com a ditadura em 1964. Assim, a modernização da profissão no país foi um processo alternativo àquele que vinha se desenhando na maioria dos países da América do Sul, outro padrão de resposta à crise profissional [...]" (MARTINS, 2014, p. 98). 
SILVEIRA, 2007; SOUSA, 2008; MIOTO, 2009; SANTOS, 2011; FÁVERO, 2011; MAGALHÃES, 2011; MOREIRA; ALVARENGA, 2011).

Este salto qualitativo deve muito as problematizações formuladas por Guerra (2000), que consolidou a visão segundo o qual os instrumentos e técnicas da profissão não possuem valor e eficácia intrínsecos. A construção e utilização de instrumentais se fundamenta nas condicionantes sociais que conformam a história do Serviço Social, em especial as intuições onde o agente profissional atua. Para além disso, segundo a autora, o uso de instrumentos e técnicas (e consequentemente dos resultados que deles advém) depende da intencionalidade dos atores da profissão, incluindo os valores e a racionalidade que subscreve sua prática.

Neste sentido o arcabouço interventivo dos assistentes sociais seria uma construção que se reportaria não apenas a uma estrutura de práticas (codificadas e esquematizadas), mas a uma capacidade constitutiva da profissão, que permite que seus agentes, num determinado nível da realidade social (o nível do cotidiano), alterem as condições objetivas e subjetivas da realidade com os quais se defrontam ${ }^{3}$.

Seguindo os caminhos abertos pelo debate contemporâneo, o objetivo do presente texto é contribuir com as discussões sobre o exercício do Serviço Social, abordando, embora não exaustivamente, os documentos e registros típicos da profissão - laudos, pareceres e relatórios -, tanto no que concerne a sua forma, quanto em relação a seu papel no âmbito institucional.

\section{OS DOCUMENTOS PROFISSIONAIS E O ESTUDO SOCIAL}

Ponto fundamental relativo aos documentos profissionais é o seu enquadramento como expressões do estudo social, forma de materializar aspectos particulares da intervenção do assistente social.

Ou seja, relatórios, laudos e pareceres são resultantes ou partes de um processo de trabalho típico do Serviço Social, que envolve as competências e atribuições privativas da profissão. Tal problema,

3 Para um aprofundamento é necessária a leitura de Guerra (2014) em a 'Instrumentalidade do Serviço Social'. 
entretanto, não é completamente claro, nem apresenta resolução consensual, necessitando de maior aprofundamento para os fins desta explanação.

No contexto brasileiro, o estudo social tem sua prática e significado definidos a partir do campo sociojurídico, com a criação e expansão das Varas de Família e Sucessões, impulsionadas pelo Código de Melo Matos ${ }^{4}$ e Código de Menores ${ }^{5}$. Nesta esfera, seu emprego estava afinado com o debate conservador, sobretudo aquele de origem norte-americana, tendo no casework sua base metodológica (MIOTO, 2009; SOUSA, 2008).

Atualmente, a prática e a concepção de estudo social foi ampliada - a partir de transformações no Serviço Social - postas pela consolidação do Projeto Ético-Político Profissional, entre o final dos anos 1970 e 1990 - bem como por alterações nas políticas sociais e no Judiciário, mudanças essas que reordenaram todo o processo interventivo da profissão, sobretudo em virtude das demandas colocadas por leis como o Estatuto da Criança e do Adolescente (ECA ${ }^{6}$, Estatuto do Idoso7, Lei Orgânica da Assistência Social (Loas) ${ }^{8}$; Lei Maria da Penha ${ }^{9}$, legislação sobre quilombolas e comunidades tradicionais ${ }^{10}$ e etc. (FÁVERO, 2011; MOREIRA; ALVARENGA, 2011).

O ponto decisivo, como lembra Fávero (2011), é que o estudo social seria uma investigação circunscrita, que teria o papel de instruir a ação de um magistrado, ou de uma instituição a ele vinculada.

Assim,

Observa-se que para o desenvolvimento deste trabalho o assistente social estuda a situação, realiza uma avaliação, emite um parecer, por meio do qual muitas vezes aponta medidas sociais e

\footnotetext{
${ }^{4}$ Decreto Federal no $17.943-A$, de 12 de outubro de 1927.

${ }^{5}$ Lei Federal no 6.697, de 10 de outubro de 1979.

${ }^{6}$ Lei Federal n 8.069, de 13 de julho de 1990.

7 Lei Federal no 10.741 , de $1^{\circ}$ de outubro de 2003.

${ }^{8}$ Lei Federal $n^{\circ} 8.742$, de 7 de dezembro de 1993.

${ }^{9}$ Lei Federal $n^{\circ} 11.340$, de 7 de agosto de 2006.

${ }^{10}$ Ato das Disposições Constitucionais Transitórias (Art. 68) e Decreto Federal $\mathrm{n}^{\circ}$ 4.887 , de 20 de novembro de 2003 , principalmente.
} 
legais que poderão ser tomadas. Na realização do estudo, o profissional pauta-se pelo que é expresso verbalmente e pelo que não é falado, mas que se apresenta aos olhos como integrante do contexto em foco. Ele dialoga, observa, registra, estabelece pareceres, apresentando, muitas vezes, a reconstituição dos acontecimentos que levaram a uma determinada situação vivenciada pelo sujeito, tido juridicamente como 'objeto' da ação judicial (FÁVERO, 2011, p. 27-28).

O estudo social surge, então, como uma dinâmica que informa o trabalho profissional, resultando em um produto documental determinado. Para se chegar a um laudo, relatório ou parecer, deve-se mobilizar outros instrumentos e técnicas, geralmente instrumentos diretos (SOUSA, 2008) - como a visita domiciliar, a entrevista, oficinas para intervenção em dinâmicas de grupo e etc.. Os documentos profissionais sistematizam impressões, análises, descrições das situações de trabalho, as quais se referem, geralmente, a um procedimento que antecede uma decisão acerca dos usuários.

Noutros termos mais precisos,

[o assistente social] Por meio de observações, entrevistas, pesquisas documentais e bibliográficas [...] constrói o estudo social, ou seja, constrói um saber a respeito da população usuária dos serviços [...] Um saber que pode se constituir numa verdade. As pessoas são examinadas, avaliadas, suas vidas e condutas interpretadas e registradas, construindose, assim, uma verdade a respeito delas (FÁVERO, 2011, p. 28).

Fávero (2011) traz à tona, assim, o problema do saber e do poder na construção de verdades sobre os usuários. Segundo ela, analisar e escrever sobre o cotidiano da população é ocupar uma posição que pode ser exercida por meio de uma relação de força de tipo vertical, tal como no conservadorismo, em que o profissional é o sujeito e o usuário um objeto (MARTINS, 2014). Nessa ótica, ao invés dos documentos profissionais serem (com todas as suas limitações) mecanismos de promoção de direitos, eles se tornam instrumentos de julgamento dos usuários: formas unilaterais de 
valoração da moral; das práticas e da condição daqueles que são atendidos pelos assistentes sociais.

Análisesapressadas, baseadasem poucasinformações(geralmente colhidas por meio de um único instrumento - como a entrevista), e com embasamento teórico frágil (dado, principalmente, quando se tenta transpor a teoria diretamente para prática, rotulando, marcando e tipificando os sujeitos e suas ações), são a melhor forma de se efetivar intervenções equivocadas, principalmente quando não se consegue ultrapassar o esquematismo e as tensões impostas pelas rotinas institucionais.

Nestas situações é fácil repetir opiniões pautadas no senso comum, ou assimilar preconceitos cristalizados no seio da própria equipe profissional, estipulando, por exemplo, que os desdobramentos da ocorrência "a" serão os mesmos de outra intervenção realizada a partir do fato "b", quando na verdade tais avaliações podem ser apenas caracterizações superficiais. Mais comum ainda é o julgamento das situações de trabalho, considerando apenas a métrica ideológica do profissional, ao invés dos interesses, valores e anseios dos usuários. Muitos assistentes sociais erram ao atribuir à população os objetivos que ela não tem, fazendo uso de posturas que vão do conservadorismo que desqualifica a moralidade do público, ao messianismo "progressista", responsável por impor aos sujeitos as missões políticas mais complexas e elevadas (IAMAMOTO; 2007)"

Dessa forma, a realização do estudo social exige um esforço de ruptura: a capacidade reflexiva de traduzir demandas, captar sentidos, compreender os sujeitos e seus contextos, a partir da legalidade específica que subscreve o seu desenvolvimento. A ação profissional deve descortinar possibilidades, abrir caminhos,

\footnotetext{
${ }^{11}$ Sobre tal problema lamamoto, de forma aprofundada, coloca que (2007, p. 11516) "[... a) de um lado, o fatalismo, inspirado em análises que naturalizam a vida social, traduzido numa visão perversa da profissão. Como a ordem do capital é tida como natural e perene, apesar das desigualdades evidentes, o Serviço Social encontrar-se-ia atrelado às malhas de um poder tido como monolítico, nada lhe restando a fazer. [...] b) de outro lado, o messianismo utópico, que privilegia as intenções, propósitos do sujeito profissional individual, num voluntarismo marcante [...] o messianismo traduz-se numa visão 'heroica', ingênua, das possibilidades revolucionárias da prática profissional, partir de uma visão mágica da transformação social”.
} 
ampliar opções, e não impor - de forma explícita ou velada. Cabe aos agentes demandatários fazer uso dos serviços, aderindo na medida de suas vontades e responsabilidades. É nessa linha tênue que se realizam as práticas comprometidas com os interesses dos grupos e classes populares, descartando a tutela para reconhecer os efetivos desdobramentos do trabalho do assistente social, direcionado a indivíduos, grupos e instituições ativos, que respondem de forma variada (e, por vezes, desafiadora) às interpelações profissionais.

Nesta perspectiva Mioto (2009), lembra que o estudo social se concretiza a partir da conjugação de dois tipos de esforços profissionais:

O primeiro concerne à interpretação das demandas postas aos assistentes sociais pelos indivíduos. Aquelas necessidades trazidas por sujeitos singulares não são mais compreendidas como problemas individuais. Ao contrário, tais demandas são interpretadas como expressões de necessidades humanas básicas não satisfeitas, decorrentes da desigualdade social própria da organização capitalista. Assim, o assistente social tem como objeto de sua ação as expressões da questão social, e essa premissa não admite que se vincule a satisfação das necessidades sociais à competência ou incompetência individual dos sujeitos.

O segundo refere-se ao redimensionamento que a perspectiva crítico-dialética exige da ação profissional no que diz respeito ao seu alcance e direcionalidade. Ao postular que as soluções dos problemas dos sujeitos singulares só se efetivam, de fato, com a transformação das bases de produção e reprodução das relações sociais [...] exige-se que a ação profissional seja pensada na sua teleologia (MIOTO, 2009, p. 481).

Por essa via o estudo social e os documentos profissionais devem se estruturar enquanto dinâmicas integradas ao processo de trabalho do assistente social, visando o alcance dos resultados capazes de contribuir com o atendimento das demandas do público do Serviço Social - o que significa considerá-los para além da sua realidade imediata, reconhecendo a conjuntura, os interesses e as ideias que os determinam. 
Importante então expor um elemento de controvérsia. O estudo social na visão aqui trabalhada não se limita ao estudo socioeconômico. Este último seria a caracterização precisa da estrutura familiar, ou das relações sociais do indivíduo, em termos de redes primárias e recursos econômicos - em geral parte de um teste de meios (GRACIANO; LEHFELD, 2010; PITARELLO, 2013). O estudo social, por sua vez, seria um processo investigativo que interroga a realidade com vistas a uma intervenção em matéria de Serviço Social (TERRA, 2000; MATOS, 2015). Assim, a análise socioeconômica, enquanto atividade meio, pode compor o estudo social, isto é, pode ser um dos instrumentos deste estudo, contudo, este necessariamente a ultrapassa. Por esse ângulo, o estudo socioeconômico seria uma competência do assistente social, tal como define o Art. $4^{\circ}$ da Lei Federal $n^{\circ} 8.662$ de 7 de junho de 1993 - que regulamenta a profissão de assistente social no Brasil -, enquanto o estudo social seria uma atribuição privativa deste profissional ${ }^{12}$, posto que exigiria análise e emissão de opinião na área de Serviço Social, se utilizando de saberes e habilidades inerentes à atuação da profissão, ao seu processo formativo e cultura institucional.

Este tópico apresenta dificuldades claras, dado que o entendimento acerca das atividades privativas do Serviço Social não é pacífico, inclusive para fins de interpretação e aplicação da legislação que rege a profissão.

Como diz lamamoto (2012)

[...] persiste [na categoria] a necessidade de explicitar com maior clareza o que é matéria de Serviço Social, área de Serviço Social e unidade de Serviço Social, especificações constantes nos incisos de I a IV do art. $5^{\circ}$ [da Lei Federal $n^{\circ}$ 8.662 de 7 de junho de 1993] [...] Ora, esta é uma

\footnotetext{
${ }_{12} 5$ - Lei Federal $n^{\circ} 8.662$, de 7 de junho de 1993 , “Art. $5^{\circ}$. Constituem atribuições privativas do Assistente Social: I - coordenar, elaborar, executar, supervisionar e avaliar estudos, pesquisas, planos, programas e projetos na área de Serviço Social; II - planejar, organizar e administrar programas e projetos em Unidade de Serviço Social; III - assessoria e consultoria a órgãos da administração pública direta e indireta, empresas privadas e outras entidades, em matéria de Serviço Social; IV realizar vistorias, perícias técnicas, laudos periciais, informações e pareceres sobre matéria de Serviço Social” (BRASIL, 1993, não paginado).
} 
exigência que remete à arena propriamente técnico-profissional e ao debate ético-político sobre o Serviço Social na atualidade. Trata-se de uma questão que é fundamentalmente da categoria, a quem cabe a sua explicitação. A análise do art. $5^{\circ}$ relativo às atribuições privativas do Assistente Social, especialmente os incisos de I a IV, indica que a maior dificuldade na identificação desse caráter privativo não se encontra na descrição ou relato da atividade a ser desenvolvida, que em si mesma não é prerrogativa de qualquer profissional em particular, como, por exemplo: coordenar, elaborar, executar, supervisionar e avaliar estudos, pesquisas e projetos; planejar, organizar é administrar projetos; realizar assessoria e consultoria a órgãos da administração pública direta e indireta, empresas privadas e outras entidades; realizar vistorias perícias técnicas, laudos periciais informações e pareceres. O que delimita o caráter da atividade enquanto privativa do assistente social é a sua qualificação enquanto matéria, área e unidade de Serviço Social. Portanto, explicitar a legislação supõe dar conta de uma questão que não pode ser tributada de imediato ao texto legal, porque cabe ao conjunto desses profissionais especializados esclarecerem a partir de sua formação teórica, técnica e ético-política (IAMAMOTO, 2012, p. 38).

Os apontamentos de lamamoto (2012) são fundamentais, uma vez que tornam nítida a importância do debate sobre os elementos que caracterizam o exercício do Serviço Social. A discussão técnica (realizada pelos próprios assistentes sociais) é essencial para dar concretude e eficácia ao arcabouço normativo que protege e orienta a atuação profissional. Este campo de diálogo e problematização exige um projeto profissional capaz de situar e significar a atuação do assistente social no mercado de trabalho, distinguindo sua contribuição frente aos diversos campos profissionais existentes.

Ou seja, ao indicar que o estudo social é estudo em matéria de Serviço Social, adentra-se no território de discussão sobre os saberes, habilidades e práticas particulares da categoria profissional, discussão essa que, longe de ser delimitada e pronta 
(o que se daria, por exemplo, pelo uso literal dos dispositivos legais) aponta para concepções e ideias que estão em construção e disputa.

Retomando a caracterização do estudo social ora empreendida, é importante destacar que aqui se esboça uma concepção diferente, por exemplo, daquela defendida por Mioto (2009), que sugere uma identidade entre o estudo socioeconômico e o estudo social. Também se amplia a discussão proposta por Fávero (2011), uma vez que tal processo passa a ser concebido para além dos limites do campo sociojurídico, constituindo uma estratégia pertinente aos mais variados espaços sociocupacionais do Serviço Social.

Podemos apresentar agora, antes de discutir outras determinações dos documentos profissionais, os principais pontos para realização de estudos sociais, os quais, na forma de perguntas e respostas, sintetizamos abaixo.

1. O que é o estudo social? É uma análise sistemática de problemas que serão alvo da intervenção do assistente social, processo realizado à luz das atribuições e conhecimentos da profissão (legislação social, rede de serviços e políticas públicas, compreensão das relações e dinâmicas familiares, escuta, acolhimento e acompanhamento, mobilização social, fortalecimento de comunidades, realização de diagnósticos, formulação de planos e projetos sociais, etc.).

2. O que torna o estudo social específico do Serviço Social? Em geral é difícil compreender a singularidade desta estratégia, uma vez que diversas categorias desempenham atividades similares àquelas realizadas pelo Serviço Social. O que particulariza o estudo social é o fato deste exigir a articulação dos conhecimentos e competências típicas da área, além de várias técnicas profissionais. Dito de outra forma: muitos advogados dominam a legislação social; psicólogos e pedagogos realizam trabalhos com famílias e grupos; muitos conhecem a rede de políticas e serviços públicos; vários sociólogos e administradores elaboram diagnósticos, planos e projetos sociais, todavia, nenhuma dessas práticas os habilitam a realizar estudos sociais. Este último diz respeito a um conjunto de saberes e ações que se referem 
a cultura e institucionalidade do Serviço Social, isto é, a uma abordagem da realidade e a emissão de opinião baseada no acumulo teórico-metodológico, técnico-operativo e nas responsabilidades ético-políticas da categoria profissional.

3. Como são feitos os estudos sociais? Os estudos sociais são processos de investigação da realidade para os fins da intervenção profissional. Não se confundem com laudos e relatórios, ou com a pesquisa acadêmica. Para realizá-los é preciso determinar a demanda de trabalho e identificar seus objetivos, os quais podem ser, por exemplo, aprofundar o conhecimento sobre um indivíduo ou família, apreender traços da realidade de grupos, organizações civis e etc., para em seguida atuar (promovendo o acesso a serviços e benefícios sociais; o fortalecimento de redes primárias e secundárias; a articulação setorial e intersetorial e etc.). Os estudos sociais exigem a mobilização de diversos instrumentos, acionados conforme as intenções que movem o processo de trabalho. Para conhecer um núcleo familiar - discriminando sua composição, dados residenciais, condições materiais, laços afetivos, potencialidades e vulnerabilidades - muitos profissionais farão uso da entrevista, da visita domiciliar e do estudo socioeconômico. Já no caso de uma intervenção sobre grupos, pode-se optar pela realização de oficinas, utilização de dados censitários, "mapas da rede" e etc. Tão importante quanto isso é a articulação dos saberes alcançados, por meio do enlace das dimensões ético-política, teórico-metodológica e técnico-operativa do Serviço Social'13. Tal passo requer uma

\footnotetext{
${ }_{13}^{13}$ De acordo com Sousa (2008, p. 121-122) a dimensão ético-política do Serviço Social diz respeito ao fato do assistente Social não ser um "[...] profissional 'neutro'. Sua prática se realiza no marco das relações de poder e de forças sociais da sociedade capitalista - relações essas que são contraditórias. Assim, é fundamental que o profissional tenha um posicionamento político frente às questões que aparecem na realidade social, para que possa ter clareza de qual é a direção social da sua prática. Isso implica em assumir valores ético-morais que sustentam a sua prática - valores esses que estão expressos no Código de Ética Profissional [...]", já a dimensão teórico-metodológica se refere a "[...] necessidade de se conhecer a realidade social, política, econômica e cultural com a qual trabalha. Para isso, faz-se necessário um intenso rigor teórico e metodológico, que lhe permita enxergar a dinâmica da sociedade para além dos fenômenos aparentes, buscando apreender sua essência, seu movimento e as possibilidades de construção de novas possibilidades profissionais [...]", por fim a dimensão técnico-operativa consiste no conjunto de habilidades técnicas que permite ao assistente social “[...] desenvolver as ações profissionais
} 
reflexão crítica, calcada em referenciais teóricos sólidos, construídos e trabalhados a partir das Diretrizes Curriculares que orientam a formação profissional ${ }^{14}$, de forma a balizar o planejamento e condução das ações. Realizado o estudo social é preciso registrá-lo, através de um laudo, relatório, ou de outros documentos similares.

4. Como os estudos sociais são afetados pela realidade profissional? Os estudos sociais são condicionados pela orientação teórica e metodológica do assistente social, cujas preferências ditarão as categorias de análise, a escolha dos instrumentais, o tratamento e a interpretação dos dados obtidos. Além disso, existem os fatores institucionais como determinantes do estudo social. Nesse âmbito a influência se estende desde os meios básicos (recursos informacionais, transporte, material para funções administrativas e etc.), até questões mais complexas, como a cultura da organização em que o assistente social trabalha, seu nível de autonomia, lugar no âmbito das políticas públicas e etc. Todos esses elementos interferem no cotidiano do exercício profissional, incidindo direta ou indiretamente no processo de realização de estudos sociais.

Há que se ter em vista que tais indicações apenas ilustram a concepção aqui adotada, não se constituindo numa formulação completa, capaz de esgotar a questão. O que se coloca são fatores básicos do estudo social e de sua conexão com os documentos profissionais, de forma a permitir que se avance na caracterização destes últimos.

\section{LAUDOS, RELATÓRIOS E PARECERES - INDICAÇÕES PRÁTICAS}

Laudos, relatórios e pareceres são formas comunicativas fundamentais para o Serviço Social, cujas determinações remetem a questão da linguagem, problema com condicionantes específicas no universo das profissões especializadas.

junto à população usuária e às instituições contratantes (Estado, empresas, Organizações Não-governamentais, fundações, autarquias etc.), garantindo assim uma inserção qualificada no mercado de trabalho, que responda às demandas colocadas tanto pelos empregadores, quanto pelos objetivos estabelecidos pelos profissionais e pela dinâmica da realidade social".

${ }^{14}$ Falamos aqui das Diretrizes formuladas pela Associação Brasileira de Ensino e Pesquisa em Serviço Social (Abepss) em 1996. 
As estruturas linguísticas, enquanto complexos organizadores de signos, símbolos e significantes, são constituídas por variantes e tipos, formuladas e usadas pelos grupos e classes sociais, que Ihes imprimem a marca da sua identidade, valores, costumes, modo de produzir e consumir. Por meio delas são realizados atos intersubjetivos em diversos meios, inclusive naqueles que transcendem o universo fonético, comportando mecanismos de expressão canalizados no corpo e nos objetos sociais (PINKER, 1984; KNIGHT; POWER, 2012).

Se a linguagem é veículo para as objetivações da comunicação, é também um modo de fixação da experiência humana, capaz de ir além da cotidianeidade, através de dispositivos que registram ou direcionam a ação e a percepção dos sujeitos. Lukács (2013) vincula sua gênese à origem do trabalho, sobretudo na forma da cooperação. Para ele, são as necessidades objetivas, materializadas nos desafios de coordenação da atividade social que estabelecem a interação linguística como um dos traços fundamentais da práxis, contribuindo, inclusive, para a expansão dos indivíduos enquanto seres autoconscientes.

Ou seja,

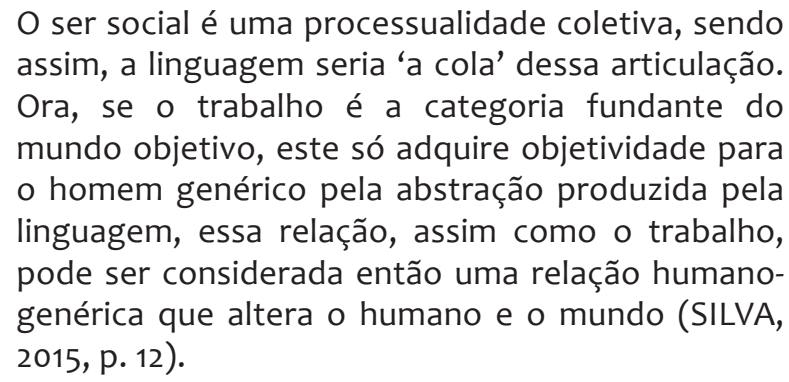

O complexo da linguagem se apresenta, nesses termos, como um mecanismo fundamental posto pelos desafios concretos da produção e reprodução social. Com o desenvolvimento da coletividade as estruturas linguísticas ampliam sua diversidade, extensão e autonomia (relativa). No modo de produção capitalista elas assumem formas e canais particulares, em virtude do desenvolvimento singular da divisão do trabalho, dos instrumentos laborais e das técnicas (constituídas nos vários 
corpos ocupacionais), o que consolida processos diversos de interação entre os sujeitos e as instituições.

Nesta esfera específica encontram-se os documentos elaborados por assistentes sociais, veículos por meio dos quais a comunicação profissional se processa, obedecendo a normas e padrões típicos desta área. Os conceitos, terminologias, a maneira de abordar as demandas e relatar o trabalho são produtos históricos que participam da reprodução social da profissão, definindo a sua identidade e cultura interventiva. A linguagem profissional principal ferramenta dos agentes da categoria - se constitui neste contexto através de manifestações escritas e orais, que efetivam o processo de trabalho do Serviço Social.

Laudos, relatórios e pareceres são dispositivos que integram este campo, tendo como característica decisiva o fato de não serem textos espontâneos. Ou seja, sua construção requer a baliza das regras e convenções da gramática normativa (MAGALHÃES, 2011; SOUSA, 2008), com suas exigências de coesão, clareza, concisão, objetividade e coerência, qualidades indispensáveis que garantem a boa transmissão da mensagem do assistente social.

Isto, todavia, não significa que seja adequado ao profissional marginalizar ou desconsiderar a linguagem do outro, tratando-a como inferior por não obedecer aos cânones da escrita formal. O assistente social deve ser capaz de compreender os padrões comunicativos do grupo que atende, de forma a traduzi-los, levando as demandas do usuário para as instituições, além de decodificar as linguagens organizacionais para o público demandatário. A capacidade de se comunicar com agentes de outras categorias e de interagir com diversas instituições também é essencial e deve pautar a construção dos textos profissionais.

No que toca aos aspectos técnicos, propriamente, a literatura apresenta apontamentos fundamentais acerca dos relatórios, laudos e pareceres (OLIVEIRA; OLIVEIRA, 2007; FÁVERO, 2011; MOREIRA; ALVARENGA, 2011; MIOTO, 2009; BAPTISTA; BATTINI, 2016).

Os relatórios são registros descritivos sobre as situações da intervenção, utilizados para fixar aspectos importantes dos fenômenos enfrentados pelos profissionais. Relatar supõe 
o preparo do locutor para dialogar com o destinatário da informação, seja este um assistente social, membro do judiciário, gestor ou um agente de outra profissão.

Há que se diferenciar, neste ato, o essencial do acessório, com base na realidade de cada situação. Se a intenção é realizar apontamentos sobre conflitos ou necessidades que permeiam grupos de socialização primária (a família extensa de um usuário, por exemplo) é necessário abordar a estrutura relacional dos agentes (parentesco, vínculos afetivos, faixa etária e etc.), mostrando como tais elementos se entrelaçam com os aspectos biográficos (acontecimentos e trajetórias individuais), determinantes culturais e econômicas (valores, ideias, origem de classe, renda, inserção no mercado de trabalho e etc.).

Porém, se o objetivo é produzir a memória documental acerca de um trabalho de acompanhamento de usuários, operado, por exemplo, na Política de Educação, pode-se indicar os desafios enfrentados pelos discentes no processo de ensinoaprendizagem; clarificar as causas imediatas dos problemas que eles vivenciam (deficiências da instituição escolar, questões familiares e da comunidade, etc.); apontar os recursos que podem ser mobilizados para atender as demandas; descrever a avaliação dos usuários sobre o serviço ofertado, isto é, abordar todos os fatores indispensáveis à caracterização das iniciativas que o assistente social desenvolveu.

É preciso entender que a natureza descritiva de um relatório não implica em neutralidade: escreve-se a partir de um ponto de vista, de um conjunto de valores e experiências sociais e pessoais que condicionam o texto. Nesses termos relatar é também avaliar, escolher o que comporá ou não a narrativa elaborada (MAGALHÃES, 2011).

Se o relatório apresenta natureza descritiva, o parecer tem perfil analítico de tom conclusivo. Segundo Fávero (2011), tal instrumento consiste na indicação sucinta da opinião profissional dirigida a um problema de intervenção, ou em uma composição dedicada a subsidiar e orientar outros agentes implicados com o atendimento do público usuário (GRACIANO; LEHFELD, 2010). Há que se verificar, em especial, sua sintonia com o relatório, visto que 
dissonâncias com este sugerem fragilidades na opinião técnica, o que pode comprometer a legitimidade do trabalho profissional.

O parecer deve se reportar às competências do assistente social, bem como ao escopo da rede de serviços, atores e organizações que este pode acionar. Não se trata aqui de negá-lo como uma ferramenta de ampliação dos limites da atuação, mas do cuidado necessário para preservar a relação dos agentes do Serviço Social com outras profissões e, principalmente, com outras organizações.

Uma questão importante se refere aos impactos deste instrumento na vida dos usuários. Por meio do parecer o assistente social se posiciona acerca da concessão de benefícios; sobre a permanência de crianças e adolescentes em seu meio familiar, a inscrição de organizações civis em conselhos de políticas públicas, a priorização de grupos e comunidades no planejamento de uma política social e etc. Cabe enfatizar que quanto mais tempo e esforço o profissional dedicar ao estudo social, recolhendo informações e refletindo sobre os problemas enfrentados menor a chance de falhas.

Outro ponto diz respeito a Resolução CFESS n 557/2009, que detalha o caráter privativo das opiniões técnicas na categoria, instituindo, inclusive, vedação a assinatura conjunta de pareceres por assistentes sociais e outros profissionais. A normativa do Conselho Federal é relevante porque valoriza as particularidades das diferentes profissões, que não podem se amalgamar com o Serviço Social, além disso, protege os usuários, ao estabelecer que as responsabilidades do assistente social frente às suas considerações e iniciativas devem ser delimitadas com clareza. Pode existir um relatório comum - que não terá a alcunha de relatório social - mas não um parecer multiprofissional (CFESS, 2009, não paginado) ${ }^{15}$.

\footnotetext{
15 O que é detalhado no Art. 4 da Resolução CFESS n 557/2009, que dispõe que "Art. $4^{\circ}$. Ao atuar em equipes multiprofissionais, o assistente social deverá garantir a especificidade de sua área de atuação. Parágrafo primeiro. $O$ entendimento ou opinião técnica do assistente social sobre o objeto da intervenção conjunta com outra categoria profissional e/ ou equipe multiprofissional, deve destacar a sua área de conhecimento separadamente, delimitar o âmbito de sua atuação, seu objeto, instrumentos utilizados, análise social e outros componentes que devem estar contemplados na opinião técnica" (CFESS, 2009, não paginado].
} 
Já o laudo, de acordo com Fávero (2011), consiste numa das materializações mais bem-acabadas do estudo social, uma vez que alude a todo o processo de avaliação e às ações realizadas pelo assistente social. Tal instrumento reúne as qualidades e exigências do relatório e do parecer (posto que é a conjunção destes), servindo para documentar a intervenção; orientar o trabalho de outros agentes; bem como indicar os caminhos da atuação profissional, prestando-se, neste caso, à sistematização de reflexões a nível prospectivo. Sua elaboração, como todo processo de trabalho, depende das finalidades da intervenção, que ditarão seus temas e extensão.

$\mathrm{Na}$ elaboração de laudos é importante assinalar de forma precisa os elementos identificadores do texto - setor em que o assistente social está lotado; número do documento; objeto; data; destinatário; nome dos usuários implicados; assinatura e carimbo. Recomenda-se, além disso, que sejam indicados os procedimentos realizados durante o estudo social - análise documental; estudo da legislação e normas institucionais; visita domiciliar, etc.; que as páginas do laudo sejam rubricadas e que as citações a artigos, livros e leis sejam feitas na forma de notas.

Concluída tal caracterização é importante trazer à tona alguns pontos acerca dos documentos profissionais, sejam estes laudos, relatórios ou pareceres. O primeiro a ressaltar se refere a questão do sigilo.

Os documentos profissionais, como dito, estabelecem a memória institucional sobre a intervenção do assistente social, são ainda meios de transmissão de informações entre diferentes agentes e organizações. Através deles aspectos fundamentais da vida dos usuários veem a luz. Diante disso, o assistente social deve ter o cuidado de controlar o número e o tipo de informações que solicita. Nada mais invasivo do que procedimentos redundantes de coleta e repasse de dados. Não adianta reunir um grande número de informações (preenchendo formulários, realizando visitas ou entrevistas) se estas não possuem relevância, ou podem expor a população.

No plano ético e técnico o profissional deve sempre escolher os meios mais contidos para solicitar dados, atendo-se apenas às informações estritamente necessárias. O compartilhamento e 
o tratamento dos registros devem seguir a mesma lógica, o que não significa o uso de um rigor estéril, capaz de inviabilizar a intervenção.

Deve-se adotar, assim, uma concepção adequada sobre o sigilo, que permita entender que devem ser colhidas e adequadamente transmitidas todas as informações importantes para enfrentar a demanda profissional. O reconhecimento da ação repousa na confiança do usuário e da rede de serviços no assistente social. Lidar corretamente com os dados, expectativas e os interesses de tais atores é um dos grandes desafios para os membros da profissão.

Ou como bem diz Albuquerque (2011, p. 110),

Aqui se enquadra a definição do limiar do que é, ou não, segredo profissional e, portanto, do que deve ultrapassar esse nível íntimo e de como deve ser traduzido. Nesta ótica, cabe ao agente gerir as fronteiras entre a indizibilidade e a publicização. $\mathrm{O}$ importante é como são construídos e explicitados os limiares, relevando de uma dada situação os elementos que podem ser 'desingularizáveis', o que não significa categorizáveis. A utilização de categorias e tipologias para enquadrar populações e procuras traduz um discurso de racionalização e homogeneização. Des-singularizar, por seu turno, é transformar uma ação íntima, privada, numa ação descriptível segundo critérios reconhecíveis por outros, sem deixar de ter em conta a especificidade da situação (ALBUQUERQUE, 2011, p. 110).

Outro elemento se refere a uma questão de cunho terminológico. Muitos profissionais se confundem ao abordar as diferenças entre laudos, relatórios e pareceres. Em vários casos os laudos são chamados por outros nomes (como parecer psicossocial ${ }^{16}$, estudo social, estudo socioeconômico e etc.). Também não é raro que as instituições empregadoras, de forma equivocada, interfiram na nomenclatura e na própria estrutura dos documentos profissionais. Esta postura se deve tanto a ingerência das organizações, quanto a falta de consenso sobre os padrões interventivos no Serviço Social, o que prejudica a categoria.

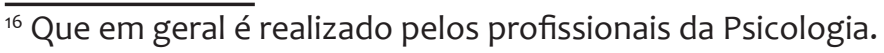


Além disso, cabe esclarecer mais um problema, concernente à forma como tais documentos interferem na legitimidade do assistente social. Quando encaminha um laudo, parecer ou relatório, o profissional está se expondo - tornando visíveis sua concepção de trabalho, capacidade de se comunicar, bem como os passos da sua intervenção.

A legitimidade se refere a credibilidade da atuação enquanto atividade apta e necessária ao atendimento das demandas dos usuários e das organizações onde o assistente social se encontra (MARTINS, 2014; 2016). Neste âmbito, os documentos são instrumentos que dependem do saber e da competência do profissional. Se um laudo é mal formulado, ou não logra êxito na transmissão da mensagem profissional, o reconhecimento do trabalho diminui ou é comprometido, o que pode causar a perda de espaços para a profissão. Por isso, a aceitabilidade dos documentos profissionais precisa ser construída, tendo em vista todos os seus destinatários.

Numa concepção mais ampla,

Isto significa que é preciso trazer, para junto da equipa, dos dirigentes, da comunidade, do setor político, os elementos das situações que podem traduzir elementos transversais a outras situações de modo a produzir respostas não paliativas [...] respostas que consigam atender a questões partilhadas, embora sem esquecer a singularidade na forma de as vivenciar e sentir por cada pessoa, família ou grupo. Se as questões são tratadas como excessivamente individuais e ficam encerradas no processo de decisão do profissional A ou B, a intervenção social não adquire a dimensão política [...] que tem necessariamente de assumir na atualidade. Desse modo, é fundamental que os profissionais consigam argumentar científica e tecnicamente as suas decisões, de modo a serem reconhecidos pelo outro, bem como evidenciar no espaço público e de poder a lógica das contradições sociais. Tal passagem para o registro público preconiza a capacidade de justificar as opções, decisões e mesmo exceções à regra, por via de argumentos passíveis de reconhecimento amplo, 
porquanto tradutores de um conjunto de princípios e valores partilhados ${ }^{17}$ (ALBUQUERQUE, 2011, p. 108).

Em outros termos: o Serviço Social, para além das possibilidades e constrangimentos de sua realidade socioinstitucional, depende de uma condução assertiva do trabalho profissional, focado nas demandas da população que atende. A valorização da intervenção é fundamental e está radicada tanto na capacidade dos assistentes sociais para oferecer respostas a seu público, quanto em sua habilidade para legitimar os termos e os resultados da sua atuação. Nesta esfera os documentos profissionais são meios privilegiados de manutenção e ampliação do reconhecimento do assistente social. Enquanto partes do processo de trabalho da categoria, eles se estabelecem como elementos formais de mediação entre o agente profissional, seus usuários imediatos, as instituições e seus atores organizacionais, conformando, em muitos casos, a visibilidade do Serviço Social.

Assim, a habilidade para produzir bons laudos, pareceres e relatórios, seja pelas necessidades técnicas, ou por demandas político-institucionais, é competência fundamental e obrigatória para os profissionais da categoria.

\section{CONSIDERAÇÕES FINAIS}

Ao abordar brevemente o problema dos documentos usados no Serviço Social é possível perceber a importância da temática, ainda que pouco trabalhada no universo crítico da profissão.

Alguns elementos fundamentais puderam ser destacados, através da reflexão sobre as definições e conceitos que tangenciam tal assunto. Nesta esfera, observar as conexões (e as distinções) entre laudos, pareceres, relatórios e o estudo social constitui-

\footnotetext{
17 Não por acaso, Albuquerque (2011, p. 110) pontua, brilhantemente, que "[...] os assistentes sociais que melhor conseguiram adaptar-se às exigências das sociedades contemporâneas, conquistando, por essa via, maior reconhecimento, foram aqueles que souberam aproveitar e alargar, por meio de uma dinâmica reflexiva e argumentativa, consistente e permanente, os limites dos contextos institucionais em que se enquadravam. Uma prática encerrada em contextos limitados (que muitas vezes não ultrapassa sequer o gabinete de trabalho), não possui, por mais qualidade que comporte, visibilidade pública e, como tal, não pode constituir-se como referência para outras práticas e como âncora de mudança social e política”.
} 
se como uma tarefa indispensável, inclusive para perscrutar as possíveis polêmicas que possam envolver a avaliação destes instrumentos.

Um ponto a se avançar refere-se às formas como os documentos profissionais são determinados pela realidade institucional. Nesse âmbito a avaliação precisa ser aprofundada para além dos documentos tradicionais, desvelando novos modos de se registrar e formalizar a atividade do assistente social, sobretudo quando vinculados ao estudo social. O que se apresenta aqui, em todo caso, são considerações ainda preliminares, as quais um dos efeitos, espera-se, seja suscitar novas e mais densas problematizações.

\section{REFERÊNCIAS}

ALBUQUERQUE, C. P. Legitimidade e reconhecimento da prática de Serviço Social: abordagem construtivista. Serviço Social em Revista, Londrina, v. 13, n. 2, p. 104-118, 2011. Disponível em: <http://www.uel.br/revistas/uel/index.php/ssrevista/article/ download/9496/9113>. Acesso em: 22 jan. 2017.

AMMANN, S. B. Ideologia do desenvolvimento de comunidade no Brasil. 3. ed. São Paulo: Cortez, 1982.

BAPTISTA, M. V.; BATTINI, O. A singularidade, a particularidade e a universalidade: para compreender a vida cotidiana. In: BAPTISTA, M. V.; BATTINI, O. (Orgs.). A prática profissional do assistente social: para reconhecer e reconstruir o cotidiano. São Paulo: Veras, 2016.

\section{CFESS. Resolução CFESS n 557/2009, de 15 de setembro} de 2009. Dispõe sobre a emissão de pareceres, laudos, opiniões técnicas conjuntos entre o assistente social e outros profissionais. Brasília (DF), 2009.

FÁVERO, E. T. O estudo social - fundamentos e particularidades da sua construção na área judiciária. In: CONSELHO FEDERAL DE SERVIÇO SOCIAL (CFESS) (Org.). O estudo social em perícias, laudos e pareceres técnicos: contribuição ao debate no Judiciário, Penitenciário e na Previdência Social. 10. ed. São Paulo: Cortez, 2011. 
GRACIANO, M. I. G.; LEHFELD, N. A. de S. Estudo socioeconômico: indicadores e metodologia numa abordagem contemporânea. Revista Serviço Social \& Saúde, Campinas, v. IX, n. 9, jul. 2010. p. 157-186. Disponível em: <http://periodicos. sbu.unicamp.br/ojs/index.php/sss/article/view/8634873/2777>. Acesso em: 29 jan. 2017.

GUERRA, Y. A instrumentalidade do Serviço Social. 10.ed. São Paulo: Cortez, 2014.

GUERRA, Y. Instrumentalidade do processo de trabalho e serviço social. Serv. Soc. Soc., São Paulo, n. 62, p. 5-34, mar. 2000.

IAMAMOTO. M. V. Projeto Profissional, espaços ocupacionais e trabalho do (a) assistente social na atualidade. In: CONSELHO FEDERAL DE SERVIÇO SOCIAL (CEFESS). Atribuições privativas do/a assistente social em questão. 1. ed. ampl. Brasília (DF): CEFESS, 2012.

IAMAMOTO. M. V. O Serviço Social na cena contemporânea. In: CFESS/ABEPSS (Orgs.). Serviço Social: direitos sociais e competências profissionais. Brasília: CFESS/ABEPSS, 2009.

IAMAMOTO. M. V. Dilemas e falsos dilemas no Serviço Social. In: IAMAMOTO. M. V. Renovação e conservadorismo no Serviço Social: ensaios críticos. 8. ed. São Paulo: Cortez, 2007.

KNIGHT, C.; POWER, C. Social conditions for the evolutionary emergence of language. In: TALLERMAN, M.; GIBSON. K. R. (Orgs). The Oxford handbook of language evolution. Nova York: Oxford University Press, 2012.

KONOPKA, G. Serviço Social de Grupo: um processo de ajuda. Rio de Janeiro: Zahar, 1972.

LEWGOY, A. M. B.; SILVEIRA, E. C.. A entrevista nos processos de trabalho do assistente social. Textos \& Contextos, Porto Alegre, n. 8, dez. 2007. Disponível em: <http://revistaseletronicas.pucrs. $\mathrm{br} / \mathrm{fo} / \mathrm{ojs} /$ index.php/fass/article/download/2315/3245>. Acesso em: 27 jan. 2017.

LUKÁCS, G. O problema da ideologia. In: LUKÁCS, G. Para uma ontologia do ser social II. São Paulo: Boitempo, 2013. 
MAGALHÃES. S. M. Avaliação e linguagem: relatórios, laudos e pareceres. 3. ed. São Paulo: Veras, 2011.

MARTINS, L. R. O pensamento de Jeannine Verdès-Leroux e o Serviço Social: um resgate crítico. Serv. Soc. Soc., São Paulo, n. 127, p. 514-532, dez. 2016. Disponível em <http://www.scielo.br/ scielo.php?script=sci_arttext\&pid=S0101-66282016000300514\&In $\mathrm{g}=$ pt\&nrm=iso $>$. Acesso em: 27 jan. 2017.

MARTINS, L. R. Determinação da legitimidade burocrática: uma alternativa a Max Weber. Temporalis, Brasília (DF), v. 15, n. 30, p. 383-403, jan. 2016. Disponível em: <http://periodicos.ufes.br/ temporalis/article/view/9578/8402>. Acesso em: 12 fev. 2017.

MARTINS, L. R. Teoria das profissões e a análise dos fundamentos do Serviço Social. Verinotio, revista on-line de Filosofia e Ciências Humanas, Belo Horizonte, n. 20, p. 64-81, out. 2014. Disponível em: <http://www.verinotio.org/ conteudo/0.46616944434696.pdf>. Acesso em: 27 jan. 2017. MONTAÑO, C. A natureza do Serviço Social: um ensaio sobre sua gênese, a "especificidade" e sua reprodução. 2. ed. São Paulo: Cortez, 2011.

MATOS, M. C. de. Considerações sobre atribuições e competências profissionais de assistentes sociais na atualidade.

Serv. Soc. Soc., São Paulo , n. 124, p. 678-698, dez. 2015.

Disponível em: <http://www.scielo.br/scielo.php?script=sci arttext\&pid=S0101-66282015000400678\&lng=pt\&nrm=iso >. Acesso em: 29 jan. 2017.

MOREIRA. M. C.; ALVARENGA, R. F. C. de. O parecer social um instrumento de viabilização de direitos. In: CONSELHO FEDERAL DE SERVIÇO SOCIAL (CEFESS) (Org.). O estudo social em perícias, laudos e pareceres técnicos: contribuição ao debate no Judiciário, Penitenciário e na Previdência Social. 10. ed. São Paulo: Cortez, 2011.

MIOTO, R. C. de T. Estudos socioeconômicos. In: CONSELHO FEDERAL DE SERVIÇO SOCIAL (CFESS); ASSOCIAÇÃO BRASILEIRA DE ENSINO E PESQUISA EM SERVIÇO SOCIAL (ABEPSS) (Orgs.). Serviço Social: direitos sociais e competências profissionais. Brasília: CFESS/ABEPSS, 2009. 
NETTO, J. P. Capitalismo monopolista e Serviço Social. 6. ed. São Paulo: Cortez, 2007.

NETTO, J. P. Ditadura e Serviço Social: uma análise do Serviço Social no Brasil pós-64. 15. ed. São Paulo: Cortez, 2011.

OLIVEIRA, A. C. M. Z. de; OLIVEIRA, S. M. de S. M. Entrevista no atendimento psicossocial de processos das varas cíveis. In: FRANCO, A. A. de P.; MELÃO, M. J. R. Diálogos interdisciplinares: a Psicologia e o Serviço Social nas práticas judiciárias. São Paulo: Casa do Psicólogo, 2007.

PINKER, S. Language learnability and language development. Cambridge: Harvard University Press, 1984.

PITARELLO, M. Seleção socioeconômica: legitimação da desigualdade na sociedade capitalista. Um estudo dos fundamentos sociohistóricos de sua operação na política social e no Serviço Social. 2013. Tese (Doutorado em Serviço Social)Programa de Pós-Graduação em Serviço Social da Pontifícia Universidade Católica de São Paulo, São Paulo, 2013.

REIS, V. T. M. Ensino do instrumental técnico de intervenção em Serviço Social: explorando possibilidades. Dissertação (Mestrado em Serviço Social)-Programa de Pós-Graduação em Serviço Social da Pontifícia Universidade Católica de São Paulo, São Paulo, 1998.

RICHMOND, M. E. El caso social individual. Madri: Talasa, 1995. RICHMOND, M. E. Diagnóstico social. Lisboa: Instituto Superior de Higiene Dr. Ricardo Jorge, 1950.

RODRIGUES DA SILVA, I. L. Redescobrindo o pensamento richmondiano: Diagnóstico social. Em debate, Rio de Janeiro, n. 4, 2006. Disponível em: <http://zip.net/bptFrM>. Acesso em: 12 fev. 2017.

SANTOS. C. M. dos. Os instrumentos e técnicas: mitos e dilemas na formação profissional do assistente social no Brasil. 2006. Tese (Doutorado em Serviço Social)-Programa de Pós-Graduação em Serviço Social da Universidade Federal do Rio de Janeiro (UFRJ), Rio de Janeiro, 2006. 
SANTOS. C. M. dos. Na prática a teoria é outra?: mitos e dilemas na relação entre teoria, prática, instrumentos e técnicas no Serviço Social. Rio de Janeiro: Lumen Juris, 2011.

SILVA, H. D. da. Educação, comunicação e emancipação humana: uma abordagem ontológica. In: ENCONTRO - MARX E O MARXISMO 2015: INSURREIÇÕES, PASSADO E PRESENTE, 2015, Niterói. Anais..., Niterói, Universidade Federal Fluminense, 2015. p. 1-18. Disponível em: <http://www.niepmarx.blog.br/MM2015/ anais2015/mc37/Tc374.pdf>. Acesso em: 23 dez. 2016.

SOUSA, C. T. de. A prática do assistente social: conhecimento, instrumentalidade e intervenção profissional. Emancipação, Ponta Grossa, v. 8, n. 1, p. 119-132, 2008. Disponível em: <http://177.101.17.124/index.php/emancipacao/article/ download/119/117>. Acesso em: 27 jan. 2017.

VASCONCELLOS, A. M. de. A prática do Serviço Social: cotidiano, formação e alternativas na área da Saúde. São Paulo: Cortez, 2002.

VIEIRA, B. O. Serviço Social: processos e técnicas. 3. ed. Rio de Janeiro: Agir, 1977.

TERRA, S. H. Parecer jurídico n. 27/98. Assunto: Análise das competências do assistente social em relação aos parâmetros normativos previstos pelo art. $5^{\circ}$ da Lei Federal n. 8.662 de 7 de junho de 1993, que estabelece as atribuições privativas do mesmo profissional. São Paulo, 2000. (Mimeo.).

TRINDADE, R. L. P. Desvendando as determinações sociohistóricas do instrumental técnico-operativo do Serviço Social na articulação entre demandas sociais e projetos profissionais. Temporalis, Brasília (DF), n. 4, p. 21-42, 2001. Disponível em: <http://cressrn.org.br/files/ arquivos/65No6Bp3Looel373q8j6.pdf>. Acesso em: 12 fev. 2017. 